\title{
THE EFFECT OF FREEZING ON CRYOSURVIVAL OF YAK SPERM
}

\author{
S. Deori* \\ ICAR-National Research Centre on Yak, Dirang-790101, Arunachal Pradesh, India
}

\begin{abstract}
A study was carried out to study the effect of freezing on cryosurvival of yak semen. Artificial insemination in yak is still in infancy. Semen cryopreservation and use of artificial insemination can be applied in yak husbandry for conservation and rapid multiplication of superior germplasm. Semen was collected from four adult yak bulls using artificial vagina method managed under uniform conditions. A total of 40 ejaculates comprising of 10 ejaculates each bull were collected following twice a week schedule and evaluated for fresh semen characteristics. The fresh yak semen characteristics viz. ejaculate volume $(\mathrm{ml})$, mass activity (0-4), initial sperm motility (\%), sperm concentration $\left(x 10^{6} / \mathrm{ml}\right)$, live sperm (\%), sperm abnormality (\%) and intact acrosome (\%) were $3.10 \pm 0.18,3.53 \pm 0.96,83.89 \pm 2.87,1180.22 \pm 42.32,77.63 \pm 4.23$, $8.45 \pm 3.33$ and $93.61 \pm 3.78$ respectively. The ejaculates were diluted (1:10) with Tris extender consisting of $6.4 \mathrm{ml}$ glycerol and $20 \mathrm{ml}$ of fresh egg yolk. Straws were equilibrated at $5^{\circ} \mathrm{C}$ for 4 hours followed by exposure to liquid nitrogen vapour for 10 minutes and finally transferred to liquid nitrogen container for storage. The cryosurvival rate was studied after 7 days of storage in liquid nitrogen. The frozen semen was thawed in warm water $\left(37^{\circ} \mathrm{C}\right)$ for 30 seconds for evaluation. Mean values of postthaw sperm motility (\%), live sperm (\%) and intact acrosome (\%) in yaks were $55.67 \pm 4.67,65.62 \pm 3.23$ and $89.26 \pm 3.67$ respectively. In conclusion, yak semen has a better cryosurvival while freezing in tris extender with 6.4 per cent glycerol and 20 per cent egg yolk following an equilibration period of $4 \mathrm{~h}$.
\end{abstract}

Keywords: Cryosurvival, freezing, semen, yak

\section{INTRODUCTION}

Yaks are reared on high altitude free-ranges/pastures in trans-Himalayan and Himalayan regions of India and its neighboring countries. It is a unique bovine

\footnotetext{
* Corresponding author e-mail: sourabhd1@ rediffmail.com
} 
species of economical importance surviving in high hills snow bound areas under hypoxic and extreme cold conditions (even at-30 to- $40^{\circ} \mathrm{C}$ ) above 3000 metre from sea level, where major agriculture is not rewarding due to non-availability of arable lands. Unlike other bovines, yak has been considered as multipurpose animal as they provide milk, meat, fibre/wool, hide, fuel and the much needed transportation to the highlanders. The yak husbandry in India is facing a lot of challenges that leads to decline in yak population. Constraints of transhumance system of yak rearing, unscientific management practices, reproductive problems, nutritional scarcity, degradation of natural pastures and weak marketing linkage are some of the major challenges that makes yak husbandry unpopular. Declining yak population has become a cause of concern to the development authorities as these animals largely cater the needs of the highlanders. Decreasing population accompanied by geographical isolation of yak herds increased the risk of inbreeding that have adversely affected the genetic potential of the animals resulting in reduction in milk production and body size (Roychoudhury and Pathak, 2016).

Cryopreservation of semen and use of Artificial Insemination (AI) can be one of the effective tools for overcoming the inbreeding problem in yaks (Deori et al., 2016). Sperm cryopreservation not essentially only preserve the genetic resources, but also supports transportation of species between remote locations. Transportation of frozen semen is easier and economical in comparison to moving the bulls for natural service. Therefore, this technique may be used successfully in yaks located in inaccessible hilly terrains. Keeping in view the above facts, the present study was designed to see the effect of freezing on the cryosurvival of yak semen and to establish a speciesspecific standard freezing protocol.

\section{MATERIALS AND METHODS}

The study was carried out in the yak farm of the institute located at 9022 feet above mean sea level in the Nyukmadung area of the West Kameng District of Arunachal Pradesh in India. Four yak bulls aged between 3.5 to 4 years were trained for semen donation by artificial vagina method. The bulls were maintained under uniform intensive system of management and fed with seasonal grass ad libitum and concentrates of maize, groundnut cake, wheat bran with additional salt and minerals. They were thoroughly examined for sexual and general health before selection. A total of 40 ejaculates comprising of 10 ejaculates from each bull were collected following twice a week schedule and evaluated for fresh semen characteristics.

Ejaculate volume was recorded directly from the glass graduated semen collection tube and expressed in millilitre. Mass activity was estimated immediately after collection of semen. A drop of semen was placed on a pre warmed $\left(37^{\circ} \mathrm{C}\right)$ glass slide and examined under low power objective at a magnification of $100 \mathrm{X}$ without cover slip. The scoring was done on the basis of wave pattern described by Zemjanis (1970). Initial sperm motility was estimated by taking a fine drop of semen diluted with $4-5$ drops of pre warmed $\left(37^{\circ} \mathrm{C}\right)$ tris buffer that consisted of $2.422 \mathrm{~g}$ tris, $1.36 \mathrm{~g}$ 
citric acid, $1 \mathrm{~g}$ fructose and $100 \mathrm{ml}$ triple glass distilled water. A drop of diluted semen was placed on a pre warmed glass slide $\left(37^{\circ} \mathrm{C}\right)$ with a cover slip on it and examined under a phase contrast microscope at a magnification of 400X. It was recorded as percentage of progressively motile sperm. Sperm concentration was determined with the help of a Neubauer counting chamber after a dilution of 1:200 with a diluting fluid and expressed in million per millilitre of semen. The percentage of live spermatozoa was determined using Eosin-Nigrosin staining technique described by Blom (1977). Sperm tail and mid piece abnormality were studied by differential interference phase contrast microscopy of wet-mount semen fixed in isotonic formal saline under high power objectives. The sperm head morphology was studied by staining the spermatozoa with Williams stain and examined under microscope of 1000X under oil immersion objectives. The morphological changes of acrosome were studied in stained semen smear using Giemsa staining technique of Watson (1975). Two hundred spermatozoa were examined in each smear at a magnification of $1000 \mathrm{X}$ of a compound microscope fitted with artificial illumination and the percentage of intact acrosome was determined.

The ejaculates were diluted (1:10) with tris extender consisting of $2.42 \mathrm{~g}$ tris, $1.36 \mathrm{~g}$ citric acid, $1.0 \mathrm{~g}$ fructose and $73.6 \mathrm{ml}$ of triple glass distilled water. To it $6.4 \mathrm{ml}$ glycerol and fresh egg yolk $20 \mathrm{ml}$ was added. Straw filling and sealing was done by filling and sealing machine at room temperature and the straws were transferred to the cold handling cabinet maintained at $5^{\circ} \mathrm{C}$. After the straws reached to $5^{\circ} \mathrm{C}$ they were equilibrated at $5^{\circ} \mathrm{C}$ for 4 hours followed by exposure to liquid nitrogen vapour for 10 minutes and storage in liquid nitrogen.

After 7 days of storage in liquid nitrogen, the frozen semen was thawed in warm water $\left(37^{\circ} \mathrm{C}\right)$ for 30 seconds for evaluation. Each semen sample was evaluated for sperm motility, live sperm, and intact acrosome after freezing as per the methods discussed previously.

\section{RESULTS AND DISCUSSION}

In the present study the fresh yak semen characteristics viz. ejaculate volume $(\mathrm{ml})$, mass activity (0-4), initial sperm motility (\%), sperm concentration (x 10\% $/ \mathrm{ml})$, live sperm (\%), sperm abnormality $(\%)$ and intact acrosome $(\%)$ were $3.10 \pm 0.18,3.53 \pm$ $0.96, \quad 83.89 \pm 2.87,1180.22 \pm 42.32,77.63 \pm 4.23,8.45 \pm 3.33$ and $93.61 \pm 3.78$ respectively. Mean values of post-thaw sperm motility (\%), live sperm (\%) and intact acrosome $(\%)$ in yaks were $55.67 \pm 4.67,65.62 \pm 3.23$ and $89.26 \pm 3.67$ respectively.

In accordance with the present findings, Hazarika et al. (2012) reported ejaculate volume, initial sperm motility, sperm concentration and live sperm count of fresh yak semen irrespective of animals to be $2.83 \pm 0.08 \mathrm{ml}, 71.5 \pm 0.57 \%, 1182.5 \pm 3.23$ million/ml and $80.05 \pm 0.74 \%$ respectively. Borah et al. (2015a) reported mean sperm motility and percent live sperm in fresh semen of yak bulls immediately after collection to be $73.00 \pm 0.84$ and $80.00 \pm 0.78$ respectively. They further recorded that following equilibration period of $3 \mathrm{~h}, 4 \mathrm{~h}$ and $5 \mathrm{~h}$ the post thaw sperm motility 
were $38.75 \pm 1.62,47.00 \pm 1.64$ and $45.00 \pm 1.49$ percent respectively with an overall mean of $43.58 \pm 1.01$. In the present study, following freezing, the sperm motility was recorded $55.57 \pm 4.67$ percent following $4 \mathrm{~h}$ of equilibration, which is higher than the reported value of Borah et al. (2015a). These may be attributed to differences in season of collection and freezing protocol used.

In an another study, Borah et al. (2015b) found post thaw live sperm in yaks ranged from $69.87 \pm 0.41$ to $70.40 \pm 0.78$ percent and percentage of total acrosomal changes ranged from $11.00 \pm 0.62$ to $13.27 \pm 0.53$ while employing different thawing methods. These values are in accordance with the present findings.

\section{CONCLUSION}

It could be concluded that yak semen has a better cryosurvival while freezing in tris extender with 6.4 percent glycerol and 20 percent egg yolk following an equilibration period of $4 \mathrm{~h}$. Frozen yak semen can be suitably used for artificial insemination to curb inbreeding and rapid multiplication of superior germplasm.

\section{REFERENCES}

Blom, E. (1977). Sperm morphology with reference to bull fertility. p. 61-81. In Proc. First All India Symposium on Animal Reproduction. Ludhiana.

Borah, B.K.D., Deka, B.C., Biswas, R.K., Chakravarty, P., Deori, S., Sinha, S., and Ahmed, K. (2015b). Effect of thawing methods on frozen semen quality of yak (Poephagus grunniens L.) bulls, Veterinary World, 8(7), 831-834.

Borah, B.K.D., Deka, B.C., Biswas, R.K., Chakravarty, P., Deori, S., Sinha, S Ahmed, K., Dutta, D. J., and Bhattacharyya, D.K. (2015a). Effect of equilibration period on post thaw semen quality of Indian yak. Indian Journal of Animal Sciences, 85 (6), 607-609.

Deori, S., Das, P.J., Paul, V., Hussain, M., Medhi, D., Bam, J., Bhattacharya, D., and Deb, S.M. (2016). Cryopreservation of semen for ex-situ conservation of Yak (Poephagus grunniens L.), p. 109. In Proc. International Conference Global Biodiversity, Climate Change and Sustainable Development, 15-18 Oct., Itanagar, India.

Hazarika, D., Sarma, S., Chakravarty, P., Kalita, D.J., Goswami, J., and Deka, B.C. (2012). Testosterone in yak (Poephagus grunniens L.) bull seminal plasma and its correlation with physical characteristics of semen. Indian Journal of Animal Sciences, 82 (7), 713714.

Roychoudhury, R., and Pathak, P.K. (2016). Scientific interventions in traditional yak management system for improving profitability. p. 30-36. In Proc. Fourth Interface Meeting on Holistic approaches to sustain livelihood of yak rearers through scientific interventions in India, 3-5 March, ICAR-NRC on Yak, Dirang, India.

Watson, P.F. (1975). Use of a Giemsa stain to detect changes in acrosomes of frozen ram spermatozoa. Veterinary Record, 97, 12-15.

Zemjanis, R. (1970). Collection and evaluation of semen. p.139-155. In Diagnostic and Therapeutic Techniques in Animal Reproduction, $2^{\text {nd }}$ ed., Williams and Wilkins Co., Baltimore. 